\title{
Fuel Costs Minimization on a Steel Billet Reheating Furnace Using Genetic Algorithms
}

\author{
Harley S. O. Santos, ${ }^{1}$ Paulo E. M. Almeida, ${ }^{2}$ and Rodrigo T. N. Cardoso ${ }^{3}$ \\ ${ }^{1}$ Postgraduate Programme on Mathematical and Computational Modeling, Federal Center for \\ Technological Education of Minas Gerais, Av. Amazonas 5253, 30510-000 Belo Horizonte, MG, Brazil \\ ${ }^{2}$ Computer Engineering Department, Federal Center for Technological Education of Minas Gerais, \\ Av. Amazonas 5253, 30510-000 Belo Horizonte, MG, Brazil \\ ${ }^{3}$ Physics and Mathematics Department, Federal Center for Technological Education of Minas Gerais, \\ Av. Amazonas 5253, 30510-000 Belo Horizonte, MG, Brazil
}

Correspondence should be addressed to Rodrigo T. N. Cardoso; rodrigoc@des.cefetmg.br

Received 19 January 2017; Revised 27 April 2017; Accepted 10 May 2017; Published 7 June 2017

Academic Editor: Luis Carlos Rabelo

Copyright (C) 2017 Harley S. O. Santos et al. This is an open access article distributed under the Creative Commons Attribution License, which permits unrestricted use, distribution, and reproduction in any medium, provided the original work is properly cited.

Metallurgy industries often use steel billets, at a proper temperature, to achieve the desired metallurgical, mechanical, and dimensional properties of manufactured products. Optimal operation of steel billet reheating furnaces requires the minimization of fuel consumption while maintaining a homogeneous material thermal soak. In this study, the operation of a reheating furnace is modeled as a nonlinear optimization problem with the goal of minimizing fuel cost while satisfying a desired discharge temperature. For this purpose, a genetic algorithms approach is developed. Computational simulation results show that it is possible to minimize costs for different charge temperatures and production rates using the implemented method. Additionally, practical results are validated with actual data, in a specific scenario, showing a reduction of $3.36 \%$ of fuel consumption.

\section{Introduction}

In rolling, a piece of material is passed between two rotating cylinders to reduce the cross-sectional area. In this process, the equipment should be able to expose the burning material to a sequence of passes [1]. Products manufactured by rolling process include plates, sheets, bobbins, profiles, bars, angles, and rebars, using steel blocks, plates, or billets as input material. Rolling can be categorized into two primary groups, hot rolling and cold rolling.

In the hot rolling process, one of the most important steps is steel reheating $[2,3]$. In this step, steel billets, plates, or blocks are heated to the temperature that will guarantee good conditions for the rolling process and the surface quality of the product. The reheating step occurs in furnaces. The purpose of reheating step is to heat loaded steel from its initial temperature, generally room temperature, to the desired temperature, using as little fuel as possible and without affecting the material soak $[4,5]$.
The operation of reheating furnaces is therefore of great importance to the ferrous metallurgy process from economic, production, and environmental viewpoints. Economically, the consumption of fuel needed for reheating can represent up to $15 \%$ of the operational cost of a rolling process [4]. With respect to productivity, a furnace capacity commonly dictates the production rate for the rollers, which means that reheating is usually the bottleneck in achieving the maximum production volume. In addition to these factors, environmental relevance is important because our World is moving towards sustainability, developing actions to decrease fossil fuel consumption, thus reducing greenhouse gas emissions.

The operation of a reheating furnace is modeled here as an optimization problem with the goal of lowest cost fuel consumption while maintaining capacity constraints and guaranteeing that steel billets are at the desired temperature after reheating, even in the presence of eventual interferences. Constraints imposed by the process are nonlinear, causing difficulties when seeking for simple solutions. Calculation of 
the steel billet temperature during the reheating process is not a straightforward task, because heat transfer to the steel billets is influenced by many factors, such as internal temperature of the furnace, flow rate of fuels, thermal values of the fuels, and flow rate of air.

Since 1970s, reheating furnace modeling and control problems have been subject of many research studies. However, there are just a few studies that address models of temperature dynamics in a furnace as a function of fuel and air flow rates, which would thus allow calculation of fuel costs. These studies have addressed mathematical modeling of heat transfer which occurs inside these furnaces using mathematical models developed to estimate temperature of the material during reheating process through simulations using internal temperatures of the furnace as input $[3,6,7]$. The study of Gorni et al. [4] demonstrates that reheated material, in this case steel plates, is heated by two forms of heat from inside of the furnace: radiation and convection. Experiments were performed measuring the temperature of plates during an entire reheating process and results were satisfactory, validating the proposed model.

In order to better describe the dynamic behavior of the furnace, Kim et al. [8] propose a modified modular neural network for the supervisory control of a reheating furnace capable of dividing a complex task into subtasks and modeling each one with an expert network. Based on a discrete state space reheating furnace model developed, a dynamic model based optimization strategy giving the optimal set points of the furnace zone temperatures and a relevant computer control system have already been presented in [9]. Furthermore, some works [10, 11] use an improved extreme learning machine (ELM) method to establish a billet predictive model between billet temperature variable and heating process variable.

It is also common to find mathematical models in the literature which describe the thermodynamic behavior of plates as a function of atmospheric temperature of reheating furnace. Some works present improvements in proportional integral derivative (PID) controllers responsible for controlling internal temperatures of the furnace in each zone, using air and fuel flow rates as measurements [12-14]. Under the black-box identification paradigm, first-order and secondorder structures with a pure time delay for a given operational point are generally selected to represent models as transfer functions. As a result, these studies obtained a reduction of fuel consumption, but they did not guarantee that consumption approached the possible optimal point.

In 2010, Xuegang et al. [15] presented the idea of transforming reheating furnace control into an optimization problem using immunological algorithms to find the best heating curve. However, their study does not include some practical constraints of the process, such as the ability to vary internal temperature of the furnace (furnace dynamics), which is a limiting factor [13]. Other unconsidered constraints were fuel and combustion air capacities. More recently, Steinboeck et al. [16] design a nonlinear model predictive controller for a continuous reheating furnace for steel slabs, which defines local furnace temperatures so that the slabs reach their desired final temperatures. A nonlinear unconstrained optimization problem is solved by standard quasi-Newton methods, without guarantee of finding global optimal.

In that type of approach, minimization of fuel consumption costs is indirectly one of the objectives, represented by the smallest integral of the internal temperature of the furnace. That is, there is not a direct relationship between temperature in the furnace and fuel cost. In addition, it is possible to find solutions with different costs that present the same integral of internal temperature. This occurs in reheating ovens because the relationship between internal temperature and fuel flow rate depends on initial conditions and exhibits different behaviors in each control zone.

Optimization, computational intelligence, and genetic algorithms have been applied in other furnace problem situations. For example, the use in the context of reheating furnace scheduling can be pointed out [17-19] to predict highly precise set points in a continuous annealing furnace [20] and to adjust the temperatures of the inner zones of a pusher furnace [21].

In this study, mathematical models which describe reheating process and, subsequently, optimization algorithms to find the optimal operating point of a furnace are developed. The proposed study is relevant because it proposes optimization models that relate fuel flow rates with billets temperature and optimization methods that minimize the total cost, respecting all process constraints. In this context, evolutionary algorithms, especially genetic algorithms, have presented satisfactory performance in the search for optimal solutions [22]. Because of this, genetic algorithms have been increasingly used in industrial applications.

The main contributions of this paper are threefold: (i) development of a mathematical differential equation model which allows for calculation of steel billet temperature in each control zone during the reheating process and the conception of a dynamic first-order system with pure time delay that determines the relationship between fuel flow rates and internal temperature of furnaces. All parameters are validated by a real-data experiment; (ii) proposition of a nonlinear optimization model for minimization of energy costs in a reheating furnace per unit time and implementation of an effective genetic algorithm as an optimization machinery with specific operators, capable of generating only feasible solutions in reasonable computational time. All parameters are set through a wide statistical experiment; and (iii) investigation of a case study in an actual furnace, in which results show that using the proposed solution for furnace operation resulted in a reduction of approximately $3.36 \%$ of energy costs, when compared to the standard operating mode.

This study is organized as follows. In Section 2, reheating process is described. In Section 3, some reheating furnace optimization models are presented. In Section 4, the methodology is presented. In Section 5, practical results are discussed. Finally, Section 6 presents some conclusions and proposals for future studies.

\section{Description of Reheating Furnaces}

Reheating furnaces, considered a fundamental part of ferrous metallurgy products manufacturing, are responsible for 
heating steel billets to desired temperatures. In this process, billets go into a furnace, are heated, and then exit at ideal temperatures for the rolling process. Generally, they are large, with dimensions on the order of 10 to $30 \mathrm{~m}$ long, and they operate at high internal temperatures (higher than $1100^{\circ} \mathrm{C}$ ).

Reheating furnace in this study is a pusher-type reheating furnace, an older design characterized by a refractory hearth. One characteristic of this type of furnace is that steel billets are placed in contact with one another inside the furnace. That is, there is no free space between billets; therefore, it is difficult to unload them. In addition, to load a new piece, another piece must first be unloaded. Another disadvantage of these furnaces is the possibility of superposition of adjacent parts, in the case that parts are significantly different in size or there is a large volume of mill scale inside the furnace. Discharged billets either are rolled and become products or are rejected and returned to a billet stock patio; it is not possible to return discharged billets to the furnace.

Pusher furnaces usually have three control zones: preheating, heating, and homogenization. The latter two, heating and homogenization, each may be further subdivided into right and left or bottom and top, depending on the structure of the furnace. When loaded into a furnace, billets first pass through preheating zone and then heating zone and finally soak zone, from where they are discharged. Preheating zone, also known as convective zone or booster zone, is characterized by the absence of burners. Instead, hot gases that originate in the subsequent zones and pass through preheating zone provide the energy for reheating process. Therefore, in preheating zone, heat transfer to billets occurs through convection. Heating zone contains burners and is usually the largest zone by volume inside a furnace. In heating zone, heat transfer to billets occurs by both convection and radiation, from refractories on the walls, from the furnace domes, and from burner flames. In this zone, billets receive the most heat, allowing the material to reach a temperature near the final desired temperature at its surface. Finally, homogenization zone, also known as soak zone or equalization zone, is the last zone through which a billet passes inside the furnace. This zone has the purpose of guaranteeing homogeneity of billets temperature through their entire volume, ensuring a low temperature difference between the hottest and coldest points. This is the hottest zone in the furnace, having an operational temperature above $1200^{\circ} \mathrm{C}$. Similar to heating zone, heat transfer in this step occurs by both convection and radiation.

A reheating furnace can use liquid or gas fuel, depending on its design and fuel availability. Gas fuels used in reheating furnaces include blast furnace gas (BFG), coke gas (CG), steel mill off-gas (SMOG), natural gas (NG), liquefied petroleum gas (LPG), and mixed gas (a mixture of other gas types). Commonly used liquid fuels include heavy oils and tarderived oils. Each fuel has specific characteristics with respect to chemical composition, energy value, and the form in which it is used [23]. Energy value of each fuel is determined by its chemical composition.

Billets rolled at temperatures lower than the optimal temperature may experience operational problems, such as increased wear on rolling chains and excessive scrapping.
These factors increase production cost and may cause failures in execution of a production plan. Hence, precise control of material temperature in reheating furnaces, performed by a cascade effect, is required. Fuel burners heat the inside of the furnace, which in turn heats steel billets. A furnace contains burners in heating and homogenization zones. For each burner, fuel flow rates and oxidant (atmospheric air) flow rate obey a stoichiometric ratio of combustion. Therefore, atmospheric air flow rate capacity can be an operational bottleneck to the process.

Another important characteristic of furnaces is the disturbance caused by variation of temperature at which billets are inserted into the furnace, that is, "loading temperature." Billets are not always inserted at same temperature, which is a function of material stock time. When loading temperature varies, it is necessary to alter fuel flow rates to maintain a controlled reheating process.

Finally, changes in production rate of the roller also cause disturbances in the internal temperature of a furnace. When rolling process stops, billet discharge is interrupted, forcing billets to remain longer inside the furnace. This extended residence time tends to overheat these billets. Therefore, if interruptions of the roller occur, fuel flow rates should be decreased.

Pusher reheating furnace used in this study is $20 \mathrm{~m}$ long and $12.80 \mathrm{~m}$ wide. Steel billets have a square cross section of $130 \mathrm{~mm}$ on each side and approximately $12 \mathrm{~m}$ long. Fuels used in the furnace were BFG and oil. The desired discharge temperature is above $1100^{\circ} \mathrm{C}$.

\section{Optimization Model of Reheating Furnace Costs}

3.1. Mathematical Model of a Steel Billet Reheating. In present study, the proposed mathematical model enables calculation of billet temperature during the entire reheating process. By adapting the model proposed by Gorni et al. [4] and considering steel billet temperature as uniform along its entire volume, energy balance of reheating process is described by the system of equations (see (1)) as follows:

$$
\begin{aligned}
\frac{d Q_{r}}{d t}+\frac{d Q_{c}}{d t} & =m c \frac{d T}{d t}, \\
\frac{d Q_{r}}{d t} & =\sigma A\left(T_{A}^{4}-T^{4}\right), \\
\frac{d Q_{c}}{d t} & =h_{c} A\left(T_{A}-T\right),
\end{aligned}
$$

where $Q_{r}$ is the amount of heat a billet receives by radiation, $Q_{c}$ is the amount of heat this billet receives by convection, $T$ is the billet temperature, $m$ is the billet mass, $c$ is the specific heat of the billet, $A$ is the area of the billet that receives heat, $T_{A}$ is the internal temperature of the furnace, $\sigma$ is StefanBoltzmann constant, and $h_{c}$ is the convective heat transfer coefficient between air and billet.

To determine temperature of the billet as a function of time, it is necessary to know the internal temperature of the furnace $(T A(t))$ during the entire reheating process. For 
a numerical solution of the system of equations (see (1)), a Runge-Kutta fourth-order method is applied [24]. Initial condition $T(0)$ is the loading temperature, that is, temperature at which billets are inserted into the furnace. It is obtained using an infrared temperature sensor, responsible for measuring the temperature at which each billet enters the furnace. The final temperature of a billet, the discharge temperature, is the most important information in the process and cannot be lower than the minimum limit necessary for the rolling process.

The internal temperature is not measured in all parts of the furnace. Furnaces usually have a single sensor for the internal temperature in each control zone. Hence, the models assume that temperature in each zone is homogeneous. In preheating zone, there is no temperature sensor. The internal temperature in this region is thus defined as a linear function that interpolates from internal temperature of the heating zone to internal temperature at the input of exhausting system.

Another important consideration in the model is the fact that specific heat of steel varies as a function of its temperature [25]. That is, for some temperature values, it is necessary to provide more energy for an increase of $1^{\circ} \mathrm{C}$.

\subsection{Relation between Internal Temperature of a Furnace and} Fuel Flow Rates. To determine relationship between fuel flow rates and internal temperature of the furnace, dynamic systems identification techniques are used for estimation of model parameters (black-box modeling). Temperature meshes of the process presented a typical response of firstorder systems with pure time delay [26].

The model is thus represented by (2) as follows:

$$
\frac{Y(s)}{X(s)}=\frac{\kappa \exp (-\sigma s)}{\tau s+1},
$$

where $\kappa$ is the system gain, $\sigma$ is a pure time delay, $\tau$ is the time constant, $Y(s)$ is the output Laplace transform (internal temperature of the furnace), and $X(s)$ is the Laplace transform of the input signal (fuel flow rates).

A model is defined for each control zone of the furnace and for each fuel. During the tests for identification of each model, flow rates of other zones are held constant. Coupling of control meshes that would determine the influence of one zone over another is not considered in this model.

3.3. Energy Cost Optimization Model. Energy cost of the reheating furnace per unit time is calculated by adding consumption of each fuel per unit time in each control zone, multiplied by its respective unit cost. For the calculation, time is discretized with an interval of $4 \mathrm{~min}$.

The decision variable corresponds to the flow of a fuel in a control zone in an instant of time. The objective function used to find the lowest cost is described by (3) as follows:

$$
\min C=\min \sum_{i} \sum_{j} \sum_{t} V_{i, j, t} P_{i}
$$

where

(i) $C$ denotes energy cost per unit time; (ii) $i$ denotes each type of fuel used in the furnace, that is, $i=1$ or 2 (BFG or oil);

(iii) $j$ denotes the control zone of the furnace, that is, $j=1$ or 2 (homogenization or soaking);

(iv) $t$ denotes each time instant considered in discretization;

(v) $V_{i, j, t}$ is the flow rate of fuel $i$ in control zone $j$ at time instant $t$;

(vi) $P_{i}$ is the unit cost of fuel $i$.

Constraints imposed on the problem are the following:

(1) Each fuel is used at maximum flow rate capacity in each control zone.

(2) Air flow rate is also at maximum capacity in each control zone.

(3) For safety purposes, internal temperature of the furnace is kept at maximum limits allowed in each control zone.

(4) Maximum limits of fuel flow rates are varied; therefore, flow rates of candidate solutions cannot change more than the allowed amount between two consecutive time steps.

(5) Steel billets discharge temperature should be higher than the minimum temperature required for the rolling process.

Equations (4) to (8) show the foregoing constraints as follows:

$$
\begin{aligned}
0 & \leq V_{i, j, t} \leq \mathrm{CAP}_{i, j} \\
0 & \leq \operatorname{Var}_{j, t} \leq \mathrm{CAPar}_{j} \\
T a_{j, t} & \leq \operatorname{TaMax}_{j} \\
\left|V_{i, j, t+1}-V_{i, j, t}\right| & \leq \Delta V_{i, j, t} \operatorname{Max} \\
T d & \geq \operatorname{TdMin},
\end{aligned}
$$

where

(i) $i$ denotes fuel type used in the furnace;

(ii) $j$ denotes control zone in the furnace;

(iii) $t$ denotes the time instant in discretization;

(iv) $V_{i, j, t}$ is flow rate of fuel $i$ in control zone $j$ at time instant $t$;

(v) $\mathrm{CAP}_{i, j}$ is the maximum flow rate capacity of fuel $i$ in control zone $j$;

(vi) $\operatorname{Var}_{j, t}$ is air flow rate in control zone $j$ at time instant $t$

(vii) $T a_{j, t}$ is the internal temperature of the furnace in control zone $j$ at time instant $t$;

(viii) $\mathrm{TaMax}_{j}$ is the maximum internal temperature of the furnace allowed in control zone $j$; 

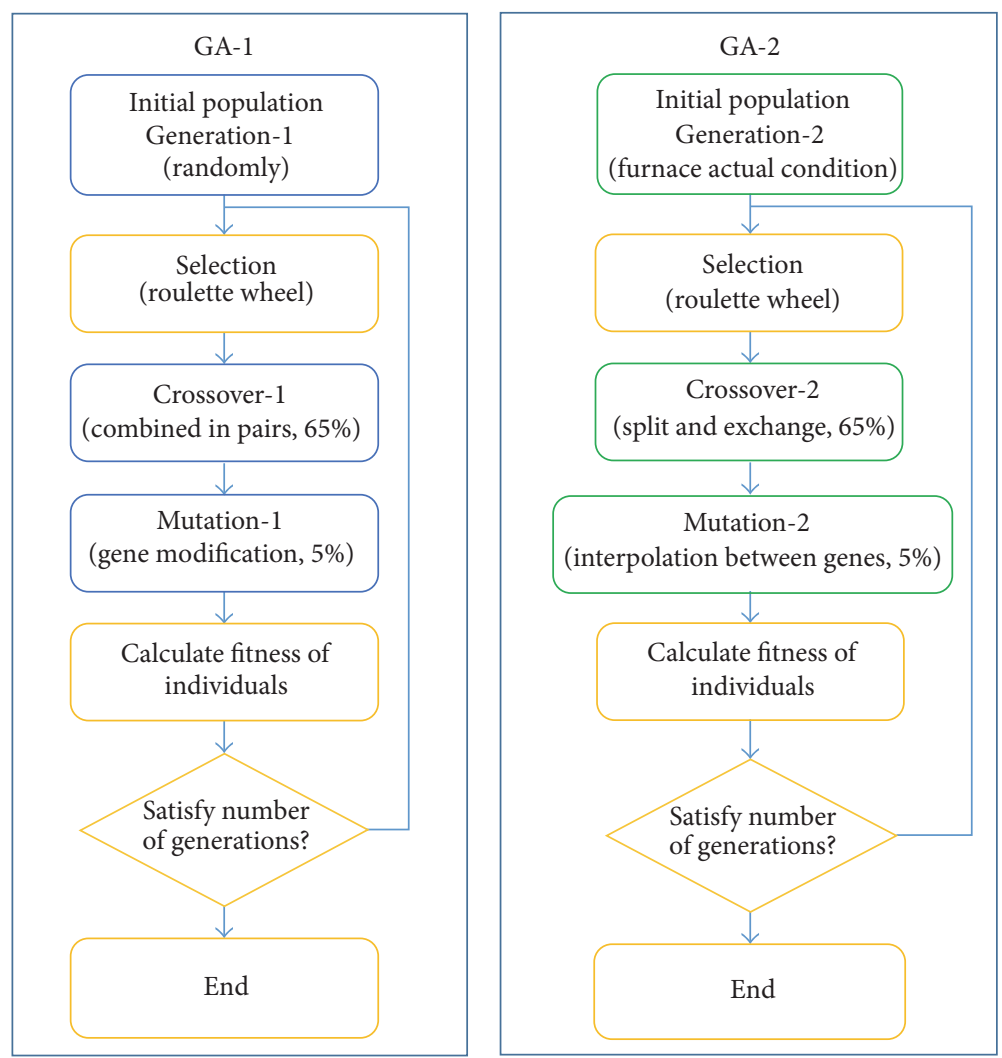

FIGURE 1: Flowcharts explaining the structure of GA-1 and GA-2.

(ix) $\mathrm{CAPar}_{j}$ is the maximum air flow rate in control zone $j$;

(x) $\Delta V_{i, j, t}$ Max is the maximum variation allowed for flow rate of fuel $i$ in control zone $j$ and time instant $t$;

(xi) $T d$ is the discharge temperature of steel billets;

(xii) $\mathrm{TdMin}$ is the minimum required discharge temperature.

In this way, a nonlinear optimization problem is formulated. To find solutions within the practical range, determining fuel flow rates in each control zone for each time instant which generates the lowest cost is not trivial. In furnace operation, the simple task of finding adequate flow rates to meet requirements represents a high degree of complexity. When adjusted manually, operators practice for many months until they are ready to operate the furnace without violating process constraints.

\section{Optimization Machinery}

To solve this nonlinear optimization problem, an approach based on genetic algorithms is selected. This choice is motivated by ability of genetic algorithms to cover the solution space in searching global optimal solutions for their flexibility to adapt to changes in the proposed problem and because of their increasing use in industrial sector [22].

Two genetic algorithms are developed specifically for this study, called GA-1 and GA-2. The two algorithms differ in the generation of initial population and in mutation and crossover processes. GA-1 is more similar to the simple form of a genetic algorithm. GA-2 is developed with the idea of including practical knowledge of the problem to help in the searching process. Figure 1 explains the general structure of both algorithms in flowcharts.

Constraints described by (4), (5), and (7) are respected during the generation of initial population and during crossover and mutation operations. Constraints represented in (6) and (8) are treated as penalty conditions, increasing the cost for individuals who violate them. Penalty is implemented by multiplying the difference between actual and desired temperatures by one thousand whenever actual temperature is higher than the desired value.

In the process of creating the optimization mechanism, the following steps are necessary: definition of individuals (codification); definition of initial population generation method; development of selection, mutation, and crossover operations; definition of the fitness function; and calculation of the cost with penalty.

The codification algorithm is such that each gene represents flow rate of a fuel in a control zone at given time instants. Each individual is defined as a set of four vectors that represent flow rates of each fuel in each control zone at each time instant. Hence, an individual represents a candidate solution for the problem and from this it is possible to verify whether constraints were respected and to find its energy cost. 
TABLE 1: Parameters found for 1st-order model for BDG and oil in each control zone.

\begin{tabular}{lcccc}
\hline Parameters & BDG homog. zone & BDG heating zone & Oil homog. zone & Oil heating zone \\
\hline$\sigma(\min )$ & 3.1 & 3.2 & 3.0 & 3.1 \\
$\kappa\left({ }^{\circ} \mathrm{C} /\right.$ flow unit $)$ & 0.005 & 0.021 & 0.018 & 0.22 \\
$\tau$ (min) & 3.9 & 3.8 & 2.3 & 2.1 \\
\hline
\end{tabular}

For GA-1, the initial population is randomly generated between minimum and maximum allowed values. In this population, some process constraints are respected; that is, flow rate of each fuel cannot be higher than its capacity, air flow rate cannot be higher than capacity, and variation of fuel flow rates between two consecutive time instants cannot be higher than a set maximum change. These constraints are also guaranteed in crossover and mutation operations. In crossover operation used in GA-1, selected individuals are combined in pairs, with a probability ratio of $65 \%$, and for each pair of individuals, flow rates of each control zone for each fuel are changed. Crossover operation generates two offspring different from parents. As a result, these new individuals are tested to verify whether they meet the constraint of maximum air capacity. If new individuals do not meet that constraint, then crossover operation is canceled and offspring becomes a copy of the parent. GA-1 mutation operation is implemented to apply a change in a given gene, with a probability ratio of $5 \%$, and, when it occurs, flow rate of a fuel at a given time is randomly modified, respecting capacity constraints and allowed variations.

In GA-2, initial population is generated from actual flow rates in the furnace at initial instant. That is, it is assumed that the operational condition of the furnace is a good estimate of the optimal solution. To create different individuals, each gene is randomly disturbed. In GA-2 crossover function, selected individuals are combined in pairs and, for each pair of individuals, flow rates are divided at a single point and information is exchanged at this point, with a probability ratio of $65 \%$. After the exchange of information, offspring are tested to verify that they obey the constraints of maximum allowed variation and maximum capacity. GA-2 mutation operation is implemented by applying a linear interpolation between two randomly selected genes in each flow rate of each control zone, with a probability ratio of $5 \%$.

The method of selection for both algorithms is a roulette type selection, where the probability of selecting an individual is proportional to its aptitude. Linear ranking is used for aptitude function. Elitism is implemented, guaranteeing that the individual with the best aptitude is selected for next generation. The stop criterion used for both algorithms is the maximum number of generations.

\section{Results}

Results from the implementation of proposed reheating mathematical model are presented. Then, results from the optimization algorithms are presented. Finally, results achieved by applying the optimizer to the furnace operation are presented.
TABLE 2: Mean absolute error of 1st-order model for BDG and oil.

\begin{tabular}{lcc}
\hline & Homog. zone & Heating zone \\
\hline BDG & 1.12 & 1.37 \\
Oil & 1.25 & 1.45 \\
\hline
\end{tabular}

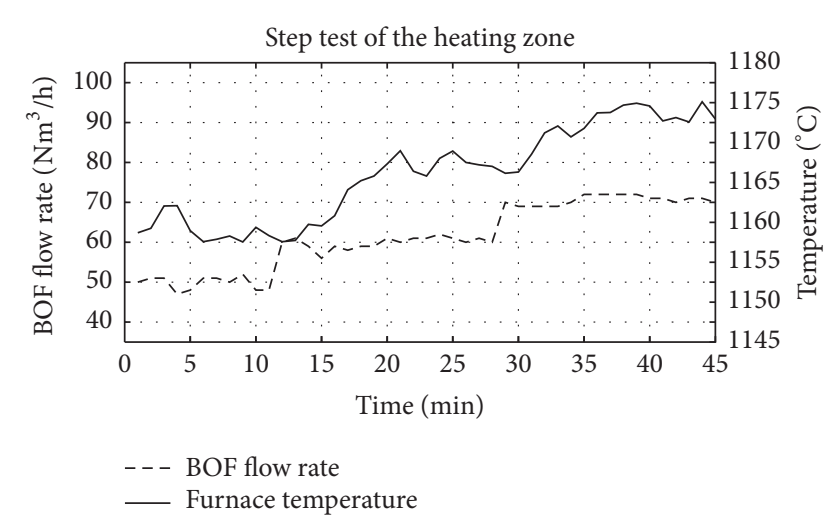

FIgURE 2: BFG (\%) and internal furnace temperature $\left({ }^{\circ} \mathrm{C}\right)$ during the identification test.

5.1. Definition of Reheating Model Parameters for Steel Billets. To validate the model relating fuel flow rates with the internal temperature of the furnace, results for actual discharge temperature are compared to the proposed mathematical model. An absolute mean error of $10^{\circ} \mathrm{C}$ is acceptable because precision of the temperature sensor is approximately $12^{\circ} \mathrm{C}$.

Initially, tests were performed by applying step size flow rate of each fuel and measuring the internal temperature of the furnace in each control zone. Graph shown in Figure 2 is a plot of test results relating BFG flow rate and the internal temperature. In this test, flow rate was increased by $10 \%$ every $10 \mathrm{~min}$ and the change in temperature was measured. With this test, the static gain $(\kappa)$, the dominant time constant $(\tau)$, and the pure time delay $(\sigma)$ for each model can be estimated. These parameters were estimated by applying the minimum mean square error to the test data. Resulting parameters are shown in Table 1.

Figure 3 shows a comparison between model predictions and actual data. Data show that the temperature proposed by the model is close to the actual temperature. Table 2 shows absolute mean errors for each model. Errors obtained with the reheating model are within allowable limits, based on expected error shown in the results of Teixeira et al. [12] and on common furnace control practice.

Hence, the model relating fuel flow rates to the internal temperature of the furnace is complete. This model is implemented in MATLAB @ (from MathWorks, USA). This model allows the internal temperature of the furnace to be 


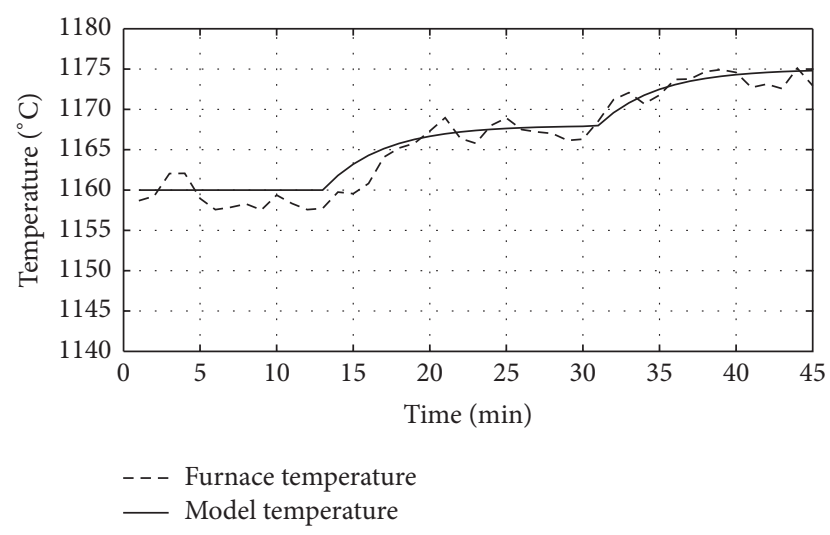

Figure 3: Actual internal temperature and temperature set by the model for heating zone.

determined from fuel flow rates during an entire reheating process. This information is then used by the reheating model in the calculation of temperature of steel billets inside the furnace. Consider the following scenario: loading temperature $(T(0)): 450^{\circ} \mathrm{C}$, inlet temperature from exhausting system: $900^{\circ} \mathrm{C}$, temperature of heating zone: $1190^{\circ} \mathrm{C}$, temperature of soak zone: $1260^{\circ} \mathrm{C}$, and reheating time: $230 \mathrm{~min}$. Figure 4 illustrates the behavior of internal temperature in the furnace and temperature of steel billets during the reheating process.

The furnace temperature data in Figure 4 show the three temperature control zones. They also illustrate heating dynamics of steel billets and the influence of the change in specific heat as a function of temperature, that is, at approximately $735^{\circ} \mathrm{C}$, after approximately $80 \mathrm{~min}$ of reheating, the temperature of steel billets indicates a decrease in heating rate. For this example, the discharge temperature of steel billets is approximately $1115^{\circ} \mathrm{C}$, an acceptable temperature for the rolling process.

To validate the steel billet reheating model, 98 data points of actual recharging temperature are compared with recharging temperatures predicted by the proposed model. Data were collected during different production scenarios with nominal production rates. Results are shown in Figure 5, which shows a dispersion graph between actual recharge temperature and recharge temperature predicted by the model. The ideal line is displayed in red, and a line which best fits the points is displayed in blue.

5.2. Definition of Parameters for the Genetic Algorithms. To define the parameters for GA-2 genetic algorithm, the model is executed by varying number of individuals and number of generations. For this comparison, the following parameters are used in the model: production per hour is $100 \%$ of the capacity and loading temperature is $250^{\circ} \mathrm{C}$. The parameters of the algorithm parameters are: number of executions, 21 , crossover probability, $65 \%$, and mutation probability, $5 \%$. To use this algorithm in process control, an optimal cost must be found in less than $10 \mathrm{~min}$.

Figure 6 shows curves of average of optimal flow rates for each population size as a function of number of generations. Data show that, generally, the optimal value improves as

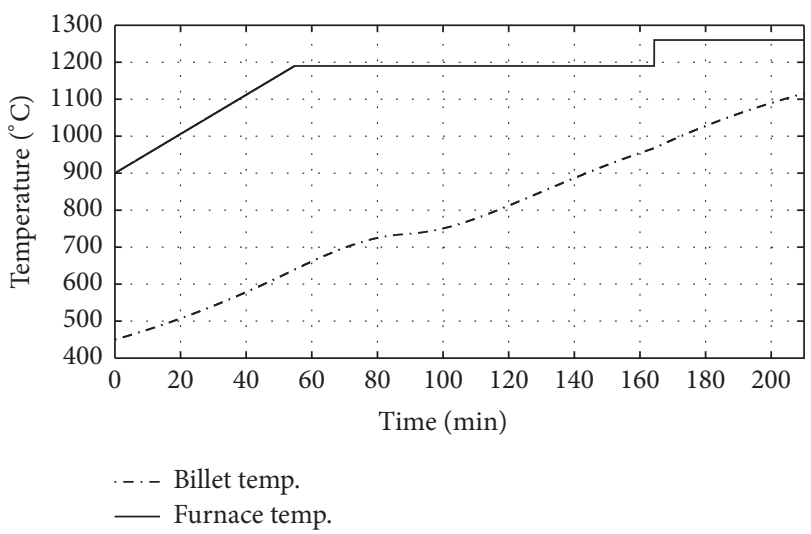

FIGURE 4: Furnace internal temperature and temperature of the billet during reheating.

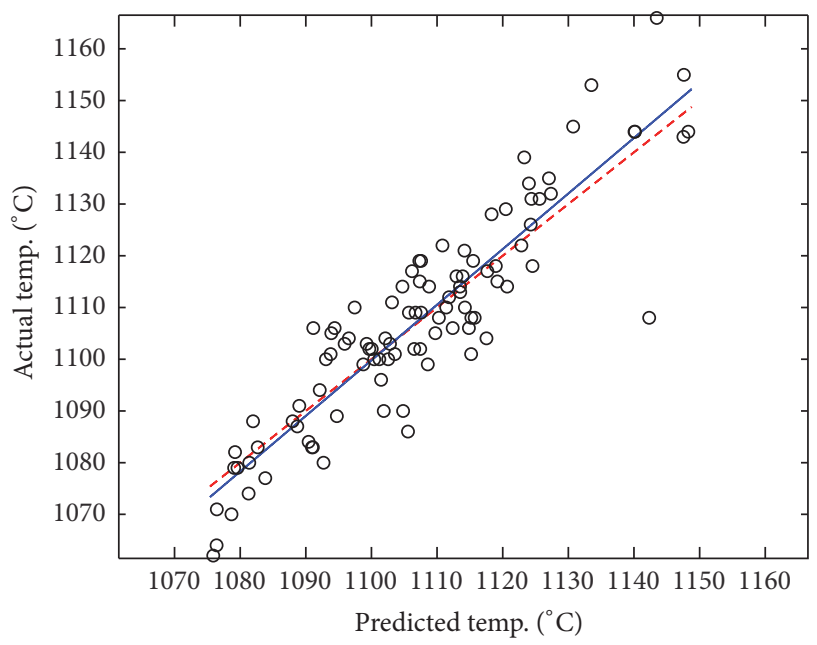

FIGURE 5: Dispersion graph between actual recharge temperature and those predicted by the model.

population size and number of generations increase. From the above tests, BFG and oil flow rates that generated the lowest cost are obtained for each configuration. Optimal flow rates are used in a normalized form in this study to comply with industrial nondisclosure.

Boxplot presented in Figure 7 shows an analysis of optimal values found among the allowed solutions. Table 3 compiles the results for the allowed solutions, indicating that configuration 6 has the lowest mean optimal value.

From the boxplots, configurations 5, 6, 7, 8, and 9 result in the lowest medians. To try to distinguish what is the best solution, the Kruskal-Wallis test, a nonparametric version of analysis of variance (ANOVA) test, implemented by kruskalwallis function in MATLAB $\odot$, is used to obtain the $p$ value. A $p$ value less than 0.05 suggests the presence of statistical evidence for rejection of the null hypothesis (data were obtained from the same population). However, obtained $p$ value suggests that, although configuration 6 has obtained the best average optimal value, we cannot state that this solution has distinct average from configurations 5 and 9 . 
TABLE 3: Compilation of results among allowed solutions from AG-2.

\begin{tabular}{lcccc}
\hline Configuration number & Total individuals & Total generations & Optimal mean value & Mean standard deviation \\
\hline 1 & 20 & 150 & 3.34 & 0.38 \\
2 & 40 & 150 & 3.23 & 0.09 \\
3 & 60 & 150 & 3.16 & 0.13 \\
4 & 80 & 110 & 3.06 & 0.21 \\
5 & 100 & 90 & 2.88 & 0.16 \\
6 & 120 & 70 & 2.84 & 0.15 \\
7 & 140 & 50 & 2.91 & 0.13 \\
8 & 160 & 50 & 2.91 & 0.08 \\
9 & 180 & 50 & 2.88 & 0.17 \\
10 & 200 & 30 & 3.03 & 0.15 \\
\hline
\end{tabular}

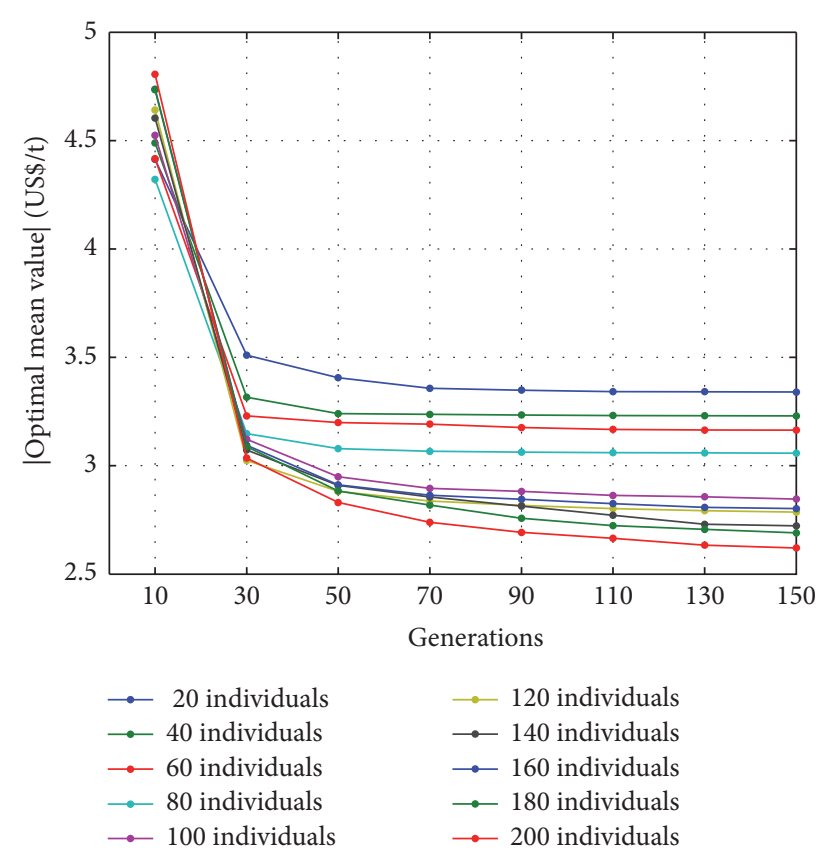

FIGURE 6: Average of normalized optimal values (US\$/t) for each of the individuals and generations of AG-2.

To evaluate results of GA-1, the algorithm was executed with different numbers of individuals and generations. For this comparison, the same parameters used in GA-2 were implemented. Table 4 shows best values found by each solution, comparing GA-1 and GA-2.

Data in Table 4 show that GA-2 yields significantly better results than GA-1 under the same conditions. Mean execution time is practically the same for both algorithms because both apply the same evaluation of the objective function, a critical operation that demands most time within the algorithm.

5.3. Optimization Results for Different Scenarios. One great advantage of using an optimizer is simplicity to simulate different input values and extracting important information from the results. In reheating furnaces, discussions on the impacts of hot furnacing and production rate are constant and bring strategic information to the industry, which are

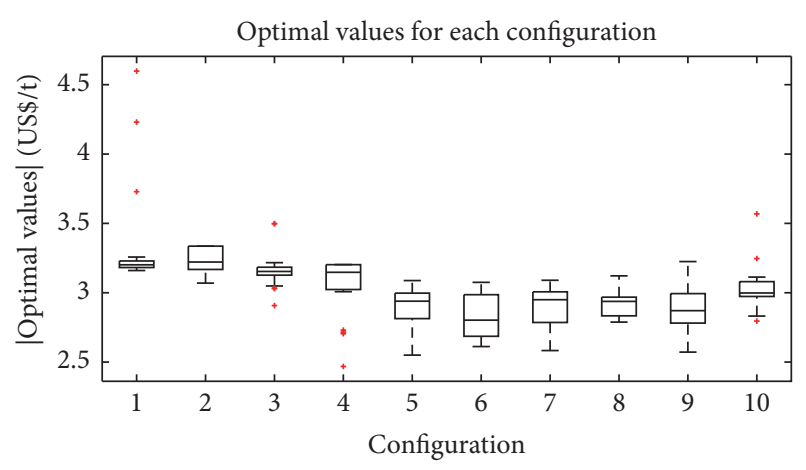

FIGURE 7: Boxplot comparing optimal solutions with allowed configurations from AG-2.

important when making decisions about investments and future goals.

Therefore, GA-2 is applied to find the optimal solution for different temperature scenarios and for three production rates: low, average, and high. For these simulations, the following algorithm parameters were used: population size of 120 individuals, number of generations equal to 70 , and number of executions, 21. Results of these simulations demonstrate that the algorithm can find practical solutions for different situations. Results are also coherent with what is observed in operational practice.

The first scenario simulates a low production rate equal to $53 \%$ of the capacity and different loading temperatures: 50,250 , and $450^{\circ} \mathrm{C}$. The full set of parameters in simulations are the following: production rate, $53 \%$ of the capacity; initial internal temperatures in the furnace, $1120^{\circ} \mathrm{C}$ in heating zone and $1170^{\circ} \mathrm{C}$ in soak zone; initial fuel flow rates, $12,000 \mathrm{Nm}^{3} / \mathrm{h}$ of BFG in heating zone, $5000 \mathrm{Nm}^{3} / \mathrm{h}$ of BFG in soak zone, $0 \mathrm{~kg} / \mathrm{h}$ of oil in heating zone, and $0 \mathrm{~kg} / \mathrm{h}$ of oil in soak zone; and loading temperatures, 50,250 , and $450^{\circ} \mathrm{C}$.

The second scenario simulates a standard production of $100 \%$ and different loading temperatures. The full set of parameters used in simulations are the following: production rate, $100 \%$ of the capacity; initial internal temperatures in the furnace, $1180^{\circ} \mathrm{C}$ in heating zone and $1220^{\circ} \mathrm{C}$ in soak zone; initial fuel flow rates, $15,000 \mathrm{Nm}^{3} / \mathrm{h}$ of $\mathrm{BFG}$ in heating zone, $9600 \mathrm{Nm}^{3} / \mathrm{h}$ of BGF in soak zone, $100 \mathrm{~kg} / \mathrm{h}$ of oil in 
TABLE 4: Comparison between results of the allowed solutions from AG-1 and AG-2.

\begin{tabular}{|c|c|c|c|c|c|c|}
\hline \# & Ind. & Gen. & AG-1 mean & AG-1 Std. & AG-2 mean & AG-2 Std. \\
\hline 1 & 20 & 150 & 9.57 & 0.77 & 3.34 & 0.38 \\
\hline 2 & 40 & 150 & 8.83 & 0.19 & 3.23 & 0.09 \\
\hline 3 & 60 & 150 & 8.90 & 0.17 & 3.16 & 0.13 \\
\hline 4 & 80 & 110 & 9.02 & 0.18 & 3.06 & 0.21 \\
\hline 5 & 100 & 90 & 8.70 & 0.27 & 2.88 & 0.16 \\
\hline 6 & 120 & 70 & 9.01 & 0.21 & 2.84 & 0.15 \\
\hline 7 & 140 & 50 & 8.84 & 0.36 & 2.91 & 0.13 \\
\hline 8 & 160 & 50 & 8.72 & 0.12 & 2.91 & 0.08 \\
\hline 9 & 180 & 50 & 8.83 & 0.19 & 2.88 & 0.17 \\
\hline 10 & 200 & 30 & 8.79 & 0.20 & 3.03 & 0.15 \\
\hline
\end{tabular}

TABLE 5: Normalized optimal values (US\$/t) due to the charge temperature $\left({ }^{\circ} \mathrm{C}\right)$ considering scenarios I, II, and III.

\begin{tabular}{lccc}
\hline Charge temperature & Scenario I & Scenario II & Scenario III \\
\hline 50 & 9.24 & 7.54 & - \\
250 & 4.47 & 2.84 & - \\
450 & 3.24 & 2.72 & 12.28 \\
\hline
\end{tabular}

heating zone, and $50 \mathrm{~kg} / \mathrm{h}$ of oil in soak zone; and loading temperatures, 50,250 , and $450^{\circ} \mathrm{C}$.

The third scenario simulates a production of $113 \%$ of capacity for different loading temperatures. The full set of parameters used in the simulations are the following: production rate, $113 \%$ of full capacity; initial internal temperatures in the furnace, $1180^{\circ} \mathrm{C}$ in heating zone and $1220^{\circ} \mathrm{C}$ in soak zone; initial fuel flow rates, $15,000 \mathrm{Nm}^{3} / \mathrm{h}$ of $\mathrm{BFG}$ in the heating zone, $9600 \mathrm{Nm}^{3} / \mathrm{h}$ of BFG in soak zone, $100 \mathrm{~kg} / \mathrm{h}$ of oil in heating zone, and $50 \mathrm{~kg} / \mathrm{h}$ of oil in soak zone; and loading temperatures: 50,250 , and $450^{\circ} \mathrm{C}$.

Table 5 shows normalized optimal mean values as a function of charge temperature for the three studied scenarios. Results show that as the loading temperature increases, optimal cost decreases. This occurs because as the loading temperature increases, less energy is required for steel billets to reheat to the desired temperature and, consequently, less energy is consumed. For temperatures of 250 and $450^{\circ} \mathrm{C}$, the solution found by the optimizer uses no oil, only BFG. Because price of BFG is very low, these two scenarios result in similar means and, consequently, similar costs. Simulation results with a loading temperature of $450^{\circ} \mathrm{C}$ show a high operational cost. This occurs because, even with hot loading, it is necessary to use the maximum fuel capacity to meet unloading temperature constraint. Results presented are consistent with operational practice because when the production rate is higher than the nominal capacity (as in the third scenario), the unloading temperature constraint is just possible to be met in the hot loading case.

5.4. Optimization Results for the Operation of an Actual Furnace. Additionally, GA-2 is applied during real-world reheating furnace operation with the purpose of verifying its
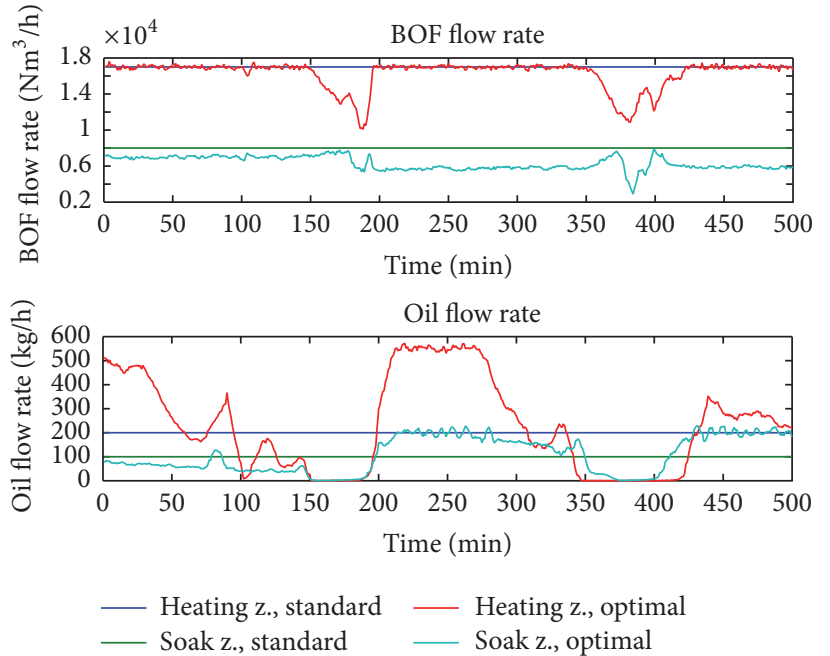

FIgURE 8: Normalized standard energy cost and optimal test energy cost found for actual reheating furnace.

effectiveness and comparing it with standard operating mode in manufacturing products.

Graph shown in Figure 8 presents flow rates determined by the optimizer and standard flow rates in operation. Data in the graph show that the optimizer found a solution with a larger variation in fuel flow rate than standard operation.

The normalized costs obtained with this experiment are the following: standard operation equal to 13.08 US\$/t and optimal operation equal to $12.64 \mathrm{US} \$ / \mathrm{t}$. This data shows that use of the solution proposed by the optimizer for furnace operation resulted in a reduction of approximately $3.36 \%$ of energy cost as compared to standard operating mode.

It should be noticed that the simple fact of controlling an actual process using the response of a simulation model is not a trivial task. The proposed model is able to meet the constraints of the real process and to reduce the fuel costs, controlling the furnace in addition.

\section{Conclusion}

This work presented an optimization model to describe the minimization of energy costs in a reheating process billets, as 
well as computation machinery based on genetic algorithms able to find reasonable solutions.

The results of the computational simulations show that this target has been satisfactorily achieved. The proposed heat transfer models had an absolute average error of approximately $6.67^{\circ} \mathrm{C}$ in predicting discharge temperature, compared with actual data of a reheating furnace. Using the implemented optimization method, it was possible to quantify costs for different charge temperatures and production rates. It is shown that the higher the charge temperature and the operation rate are, the lower the optimum fuel costs are. Furthermore, it is possible to find a solution capable of operating above the nominal production rate for high charge temperatures.

Additionally, an experimental test was shown, considering a sample process in a specific scenario of production, with the duration of $500 \mathrm{~min}$. Results showed that the optimal solution found by the algorithm met the constraints of the actual process and provided a cost $3.36 \%$ lower than a commonly used standard solution. Hence, this test presented satisfactory results. We believe that the reduction of costs should be greater using the algorithm to control the process for a long time.

As future work, we suggest the use of finite element models for reheating modeling and parallel programming techniques to decrease algorithms' run time.

\section{Conflicts of Interest}

The authors declare that they have no conflicts of interest.

\section{Acknowledgments}

The authors would like to acknowledge CEFET-MG and Brazilian Agencies CAPES, FAPEMIG, and CNPq for the financial support.

\section{References}

[1] P. R. Cetlin and H. Helman, Fundamentals of Mechanical Conformation of Metals, Artliber Editors, São Paulo, Brazil, 2nd edition, 2005.

[2] H. S. Ko, J. S. Kim, T. W. Yoon, M. Lim, D. R. Yang, and I. S. Jun, "Modeling and predictive control of a reheating furnace," in Proceedings of the American Control Conference, pp. 2725-2729, June 2000.

[3] L. L. Miranda, M. Ziviani, and B. Fullin Júnior, "Mathematical modeling of the wb2 reheating furnace of ACESITA's hot strip mill," Tecnologia em Metalurgia e Materiais, vol. 3, no. 2, pp. 34$38,2006$.

[4] A. A. Gorni, V. B. Formica, and O. Bogdan, "Comparison between approaches to mathematical modeling of thermal plates profile during reheating," REM, vol. 33, no. 3, pp. 203209, 2000.

[5] W. H. Chen, Y. C. Chung, and J. L. Liu, "Analysis on energy consumption and performance of reheating furnaces in a hot strip mill," International Communications in Heat and Mass Transfer, vol. 32, no. 5, pp. 695-706, 2005.
[6] A. A. Santos, C. P. Schiavo, and C. N. Giacomin, "Computer simulation of slab reheating process in walking beam furnaces," Tecnologia em Metalurgia e Materiais, vol. 5, no. 1, pp. 35-39, 2008.

[7] S. Strommer, M. Niederer, A. Steinboeck, and A. Kugi, "A mathematical model of a direct-fired continuous strip annealing furnace," International Journal of Heat and Mass Transfer, vol. 69, pp. 375-389, 2014.

[8] Y. I. Kim, K. C. Moon, B. S. Kang, C. Han, and K. S. Chang, "Application of neural network to the supervisory control of a reheating furnace in the steel industry," Control Engineering Practice, vol. 6, no. 8, pp. 1009-1014, 1998.

[9] Y.-Y. Yang and Y.-Z. Lu, "Dynamic model based optimization control for reheating furnaces," Computers in Industry, vol. 10, no. 1, pp. 11-20, 1988.

[10] Y.-W. Chen and T.-Y. Chai, "Modelling and prediction for steel billet temperature of heating furnace," International Journal of Advanced Mechatronic Systems, vol. 2, no. 5-6, pp. 342-349, 2010.

[11] Y. Mao, D. Xiao, and D. Niu, "Modeling, Prediction, and Control of Heating Temperature for Tube Billet," Mathematical Problems in Engineering, vol. 2015, Article ID 576813, 2015.

[12] B. S. O. Teixeira, F. G. Jota, and M. H. Teixeira, "Modeling, Control and Optimization of Slab Reheating Furnace Process," Controle \& Automao, Natal, vol. 18, no. 1, pp. 57-93, 2007.

[13] M. H. Teixeira, F. G. Jota, R. A. Carmo, and C. A. S. Oliveira, "Application of advanced control at reheating furnace of hot strip mill plants of usiminas," Tecnologia em Metalurgia e Materiais, vol. 4, no. 1, pp. 30-35, 2007.

[14] S. M. Zanoli and C. Pepe, "Two-layer linear MPC approach aimed at walking beam billets reheating furnace optimization," Journal of Control Science and Engineering, vol. 2017, Article ID 5401616, p. 15, 2017.

[15] S. Xuegang, Y. Chao, and A. Zhengang, "Setpoint optimization for billet reheating furnace based on dynamic immune algorithm," in Proceedings of the International Conference on Electrical and Control Engineering, ICECE 2010, pp. 1888-1891, chn, June 2010.

[16] A. Steinboeck, D. Wild, and A. Kugi, "Nonlinear model predictive control of a continuous slab reheating furnace," Control Engineering Practice, vol. 21, no. 4, pp. 495-508, 2013.

[17] S.-S. Ning, W. Wang, and Q.-L. Liu, "Optimal scheduling algorithm for reheating furnace in steel production," Control and Decision, vol. 21, no. 10, p. 1138, 2006.

[18] J. S. Broughton, M. Mahfouf, and D. A. Linkens, "A paradigm for the scheduling of a continuous walking beam reheat furnace using a modified genetic algorithm," Materials and Manufacturing Processes, vol. 22, no. 5, pp. 607-614, 2007.

[19] D. Xu, Q. Zhang, C. Lu, and S. Liu, "NSGA-II for slab selecting and reheating furnace scheduling in hot rolling production," in Proceedings of the 28th Chinese Control and Decision Conference, CCDC 2016, pp. 6776-6779, chn, May 2016.

[20] A. Sanz-Garcia, J. Fernandez-Ceniceros, F. Antonanzas-Torres, A. V. Pernia-Espinoza, and F. J. Martinez-De-Pison, "GAPARSIMONY: A GA-SVR approach with feature selection and parameter optimization to obtain parsimonious solutions for predicting temperature settings in a continuous annealing furnace," Applied Soft Computing Journal, vol. 35, article no. 3006, pp. 13-28, 2015.

[21] Y. X. Liao, J. H. She, and M. Wu, "Integrated hybrid-PSO and fuzzy-NN decoupling control for temperature of reheating 
furnace," IEEE Transactions on Industrial Electronics, vol. 56, no. 7, pp. 2704-2714, 2009.

[22] D. Goldberg, Genetic Algorithms in Search, Optimization and Machine Learning, Addison-Wesley, Boston, Mass, USA, 1989.

[23] G. A. C. Hauck and L. L. Laia, Reheating Furnaces, Brazilian Association for Metallurgy and Materials (ABM), São Paulo, Brazil, 2002.

[24] J. D. Faires and R. L. Burden, Numerical Analysis, Cengage Learning, Calif, USA, 9th edition, 2011.

[25] C. H. M. Alves and Filho., Analysis of cooling rate influence on microstructural gradient on hot laminated bars thermally treated [Ms.C thesis], PUC-PR, Curitiba, Brazil, 2004.

[26] S. Haykin and B. Van Veen, Signals and Systems, Wiley \& Sons Inc, NJ, USA, 2nd edition, 2003. 


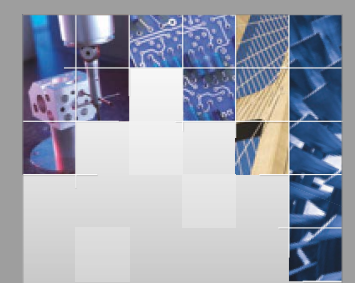

\section{Enfincering}
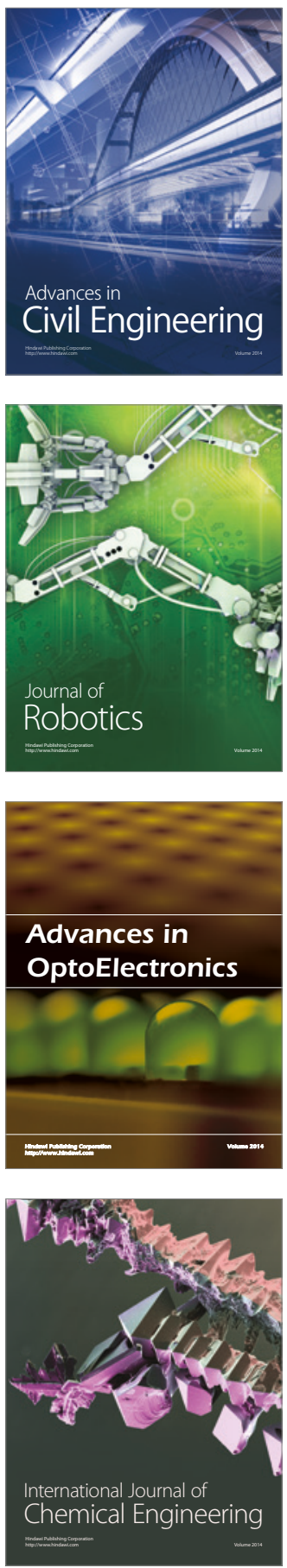

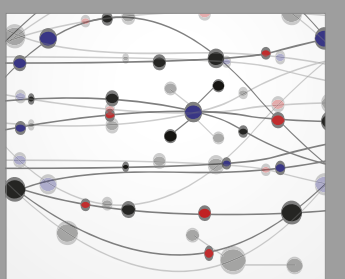

The Scientific World Journal

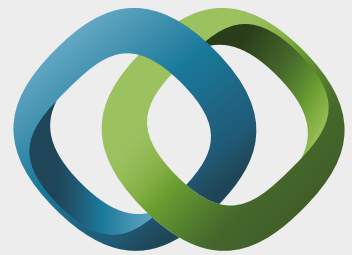

\section{Hindawi}

Submit your manuscripts at

https://www.hindawi.com
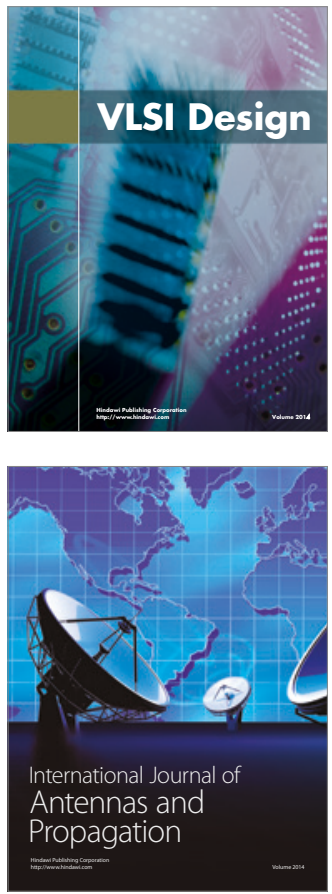

\section{Rotating}

Machinery
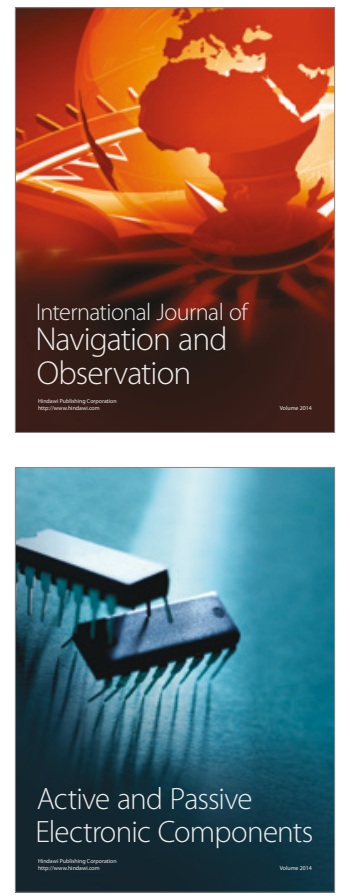
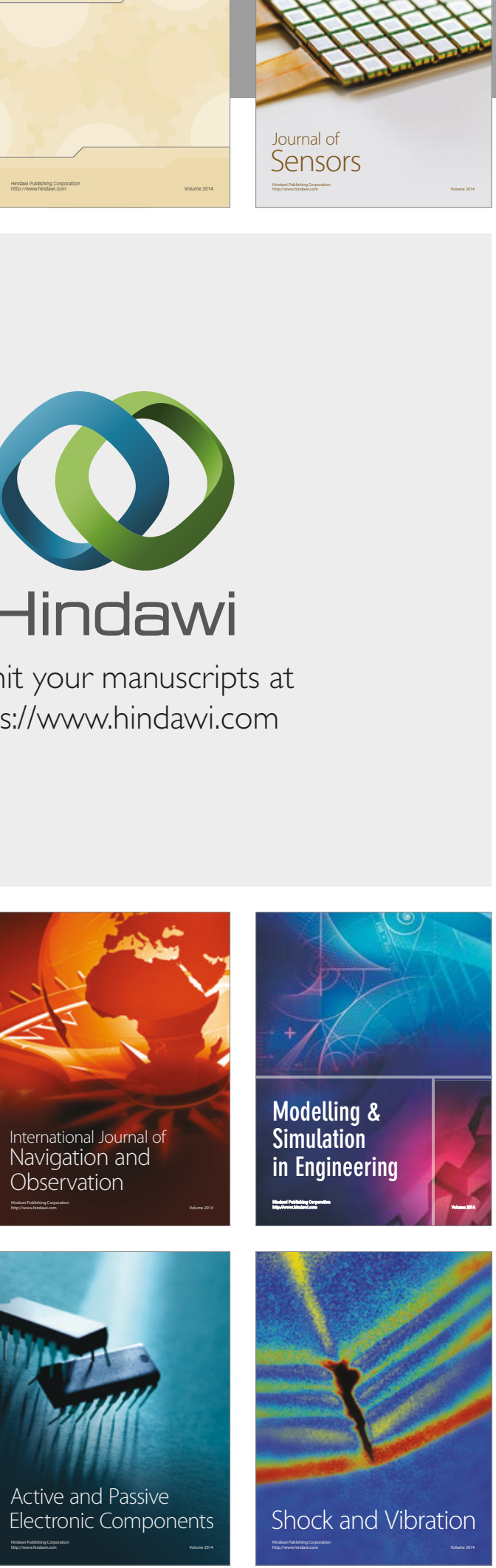
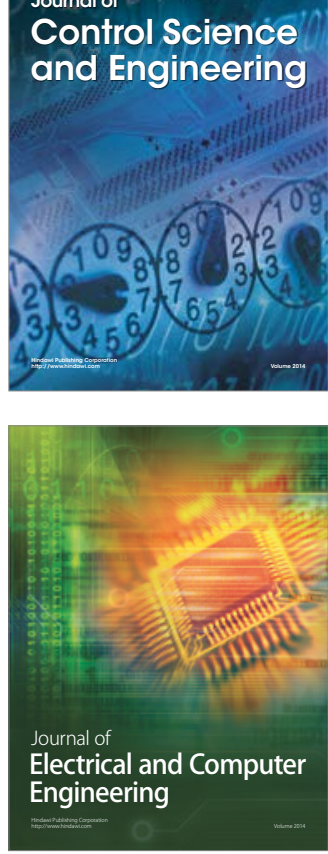

Distributed

Journal of

Control Science

and Engineering
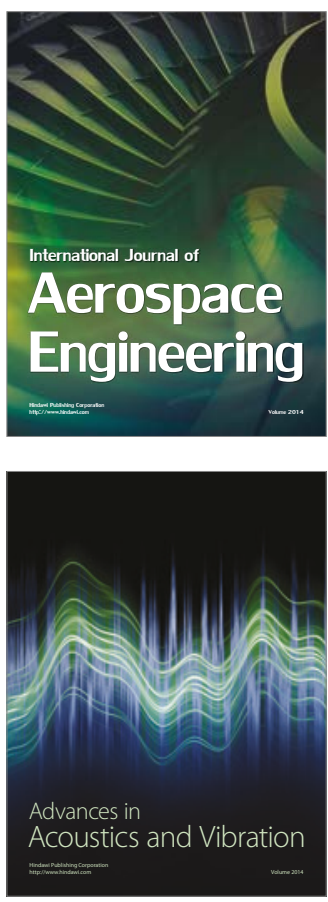

Sensor Networks 